\title{
Mobile HIV Testing Through Social Networking Platforms: Comparative Study
}

Piao-Yi Chiou ${ }^{1,2}$, PhD; Nai-Ying Ko ${ }^{3}, \mathrm{PhD}$; Chien-Yu Chien ${ }^{2}$, BSc

${ }^{1}$ Department of Nursing, National Taiwan University Hospital, Taipei City, Taiwan

${ }^{2}$ School of Nursing, College of Medicine, National Taiwan University, Taipei City, Taiwan

${ }^{3}$ Department of Nursing, College of Medicine, National Cheng Kung, Tainan, Taiwan

\section{Corresponding Author:}

Piao-Yi Chiou, $\mathrm{PhD}$

School of Nursing

College of Medicine, National Taiwan University

No 2-1, Xuzhou Road, Zhongzheng District

Taipei City, 100

Taiwan

Phone: 886223123456 ext 88427

Email: purechiou2@gmail.com

\section{Abstract}

Background: Improving HIV screening in key populations is a crucial strategy to achieve the goal of eliminating AIDS in 2030. Social networking platforms can be used to recruit high risk-taking men who have sex with men (MSM) to promote the delivery of voluntary counseling and testing (VCT) as mobile HIV testing. Therefore, client recruitment and availability of mobile HIV testing through social networking platforms requires further evaluation.

Objective: The aim of this study is to compare the effects of targeting high risk-taking MSM and HIV case finding between two mobile HIV testing recruitment approaches: through the traditional website-based approach and through social networking platforms.

Methods: A comparative study design and propensity score matching was applied. The traditional VCT model, that is, the control group, recruited MSM through a website, and a trained research assistant visited the walk-in testing station at a gay village on Friday and Saturday nights. The social networking VCT model, the experimental group, recruited MSM from social networking platforms by periodically reloading into and conducting web-based discussions on dating apps and Facebook. The participants then referred to others in their social networks via a popular messenger app in Taiwan. The test was conducted at a designated time and place during weekdays by a trained research assistant. Across both modes of contact, before the mobile HIV testing, participants needed to provide demographic characteristics and respond to a questionnaire about HIV risk-taking behaviors.

Results: We recruited 831 MSM over 6 months, with a completion rate of $8.56 \%(616 / 7200)$ in the traditional VCT model and $20.71 \%$ (215/1038) in the social networking VCT model. After propensity score matching, there were 215 MSM in each group (mean age 29.97, SD 7.61 years). The social networking model was more likely to reach MSM with HIV risk-taking behaviors, that is, those seeking sexual activity through social media, having multiple sexual partners and unprotected anal intercourse, having experience of recreational drug use, and never having or not regularly having an HIV test, compared with the traditional model. HIV positive rates (incidence rate ratio $3.40,95 \% \mathrm{CI} 1.089-10.584 ; P=.03$ ) and clinic referral rates (incidence rate ratio 0.03 , 95\% CI $0.001-0.585 ; P=.006)$ were significantly higher among those in the social networking VCT model than in the traditional VCT model.

Conclusions: Through effective recruitment strategies on social networking platforms, the social networking VCT mode can be smoothly promoted, as compared with the traditional VCT model, to target high risk-taking MSM and increase testing outcomes.

(J Med Internet Res 2021;23(3):e25031) doi: 10.2196/25031

\section{KEYWORDS}

HIV testing; internet-based intervention; men who have sex with men; mobile apps; mobile phone; risk-taking; social networking; voluntary counseling and testing 


\section{Introduction}

\section{Background}

Improving HIV screening in key populations is a vital strategy to reach the goal of 95-95-95 and eliminating AIDS in 2030 [1]. A study estimated that $88 \%$ of people with HIV in Taiwan were aware of their infection status in 2019 [2]. In addition to the current screening model, a more effective testing approach should be applied, such that $12 \%$ of the undiagnosed targets also undergo HIV testing.

Men who have sex with men (MSM) who had demonstrated unsafe sexual behaviors constitute a major group with HIV infection in Taiwan and globally $[3,4]$. To improve the uptake of voluntary counseling and testing (VCT) of MSM, mobile HIV testing, which emphasizes on the use of vehicles to deliver VCT into the community, was developed [5,6]. Mobile HIV testing employs VCT outside hospitals to target different populations and hard-to-reach groups [7-10]. To improve the HIV case findings, mobile HIV testing information should be effectively disseminated.

Usually, the client awareness of mobile HIV testing mainly results from its announcement on several platforms such as websites, radio, flyers, posters, and notifications by advocates [7-10]. Due to the high availability of smartphones, social network platforms that include mobile geosocial network apps (GSN apps) with GPS (eg, Grindr, Jack'd, and Hornet) and web-based communities (eg, Facebook [FB]) have gained a large number of web-based users and have become a popular avenue for MSM to search for health information and meet sexual partners [11-14]. High risk-taking behaviors for HIV infection, such as having multiple sexual partners, low frequency of condom use, and a high percentage of recreational drug use, have increased by using social networking platforms [15-18]. Therefore, the use of social networking platforms may also help gather mobile HIV testing information and encourage VCT among high risk-taking MSM [19,20].

In this research, HIV testing-eliciting messages and web-based discussions over instant messaging through social networking platforms were used to encourage the use of HIV VCT and self-testing among MSM [21-25]. However, there is an urgent need for more effective recruitment measures with tailored operations of social networking platforms among high risk-taking MSM. MSM users on social networking platforms could change depending on the time and place of the user who $\operatorname{logs}$ in. Active strategies, such as periodically reloading into GSN apps at different times and locations and setting up a fun page on popular web-based communities, could increase opportunities for web-based users to expand the information exposure of mobile HIV testing. The inability to coordinate time and location is one of the major barriers for MSM to reach the VCT [26,27]. Providing more flexible and individual HIV screening times and locations for MSM users could facilitate the accessibility of mobile HIV testing.

In summary, social networking platforms could be a direct path to target high risk-taking MSM. It is necessary to promote mobile HIV testing via social networking platforms, to deliver
VCT according to the assigned time and location by MSM, and to verify the effects of HIV case finding outcomes.

\section{Objective}

The objective of this research is to compare the effects of targeting high risk-taking MSM and HIV case finding between 2 mobile HIV testing recruitment approaches: through the website and through social networking platforms.

\section{Methods}

\section{Study Design}

A comparative study design was applied, wherein two VCT models were evaluated, and purposive sampling was employed. The traditional VCT model is the most popular model in Taiwan and was therefore chosen as the control group. Specifically, VCT would be applied at a certain period of time at a testing station in the community; this implementation was announced through a website. In contrast, the social networking VCT model included scheduling through social networking platforms and providing VCT at designated times and places. The most popular social networking platforms, namely, Grindr, Hornet, Jack'd, FB, and Line (a popular mobile instant messaging app in Taiwan), were selected based on the previous year's data (MOHW106-CDC-C-114-000115). The study covered the period from May 1, 2018, to November 1, 2018, in Taipei and New Taipei City. These two cities were chosen because of their higher prevalence rates of HIV infection in Taiwan.

\section{Participants}

Inclusion criteria were self-reporting as MSM, having sexual experience, being older than 20 years, and being literate. Exclusion criteria were those who self-reported as not MSM, not having any sexual experience, and previously known to be HIV positive.

\section{Ethical Considerations}

The study was approved by the institutional review board of a medical center (18MMHISO25e). All the participants' data were processed anonymously using codes. During the HIV confirmation test process, the participants did not need to disclose any personally identifiable information to the research team to maintain their privacy. After completing the consultation, questionnaire, and testing, each participant was eligible to receive a gift worth US \$3.27.

\section{Procedure and Data Collection}

\section{Traditional VCT Model}

The testing information of the traditional VCT model included free and anonymous HIV rapid testing; the testing time and location were announced every day during the study period via the public website of a municipal hospital. The traditional VCT model was conveyed to a screening station located at the entrance of a gay village between 6 PM and 10 PM every Friday and Saturday in Taipei City. The participants could actively browse the website, pass and see the outreach station, or be referred by their networks to learn about the testing information and to access the VCT. Moreover, the traditional VCT model provides walk-in services without an appointment. 
A trained research assistant conducted pretest counseling and explained the research design and purpose. After obtaining written informed consent, the participants were asked to complete a questionnaire, and the pre- and posttest counseling of the rapid HIV test was performed for each participant. The participants were informed of the test results immediately after the test. For the participants with a positive test result, the research assistant accompanied them to the clinics for further confirmation via a diagnostic test. For the participants with a negative result, crucial resources about HIV prevention, such as pre-exposure prophylaxis (PrEP) and postexposure prophylaxis (PEP), were introduced, and a referral was made for them.

\section{Social Networking VCT Model}

The social networking VCT model recruited MSM from social networking platforms and provided a free and anonymous rapid HIV test at a time and place designated by the participants.

A profile heading with mobile HIV testing and a picture of a well-trained research assistant was set up (Figure 1) in the GSN apps: Grindr, Hornet, and Jack'd. The profile clearly introduced the program's purpose; the name of the entrusted planning unit; reservation for delivering a free, anonymous, and negotiable screening time and place; and the content of HIV testing services to enhance the audience's trust [28]. The users appear on a grid with 3 to 4 profile photos in each column in Grindr, Hornet, and Jack'd, who were within a 7-mile radius from the research assistant. The main log-in location of the research assistant was the program institution at Shipai Road, Beitou District, Taipei City. The other log-in locations changed according to the designated testing locations of the participants in Taipei and New Taipei City. Two strategies of client mobilization and recruitment were applied to the GSN apps [20,29,30]: (1) reloading once every 2 hours, a total of 4 times per day, from $10 \mathrm{AM}$ to noon and 1:30 PM to 7:30 PM, on weekdays, onto each app to display our heading and profile, and allow nearby web-based users who were interested in mobile HIV testing to actively tap or send a private message to the research assistant, and (2) the research assistant provided one-on-one web-based discussions by using standard contents, including the research purpose, the privacy and rights of the participants, risk-taking behavior, and the window period of HIV infection. Individual mobile HIV testing appointments were decided after discussion.

An FB fun page (Figure 2) was created with mobile testing in Taipei City under the top section of the page with the mobile HIV testing poster images, and a clear description of the mobile HIV testing was provided to raise awareness and build rapport with the users on FB. Potential participants on FB who were interested in mobile HIV testing could send a private message to have a one-on-one discussion and make an appointment with the research assistant using standard content. A previous study used a similar recruitment method using FB [31]. 
Figure 1. The profile of the mobile HIV testing in geosocial network apps.
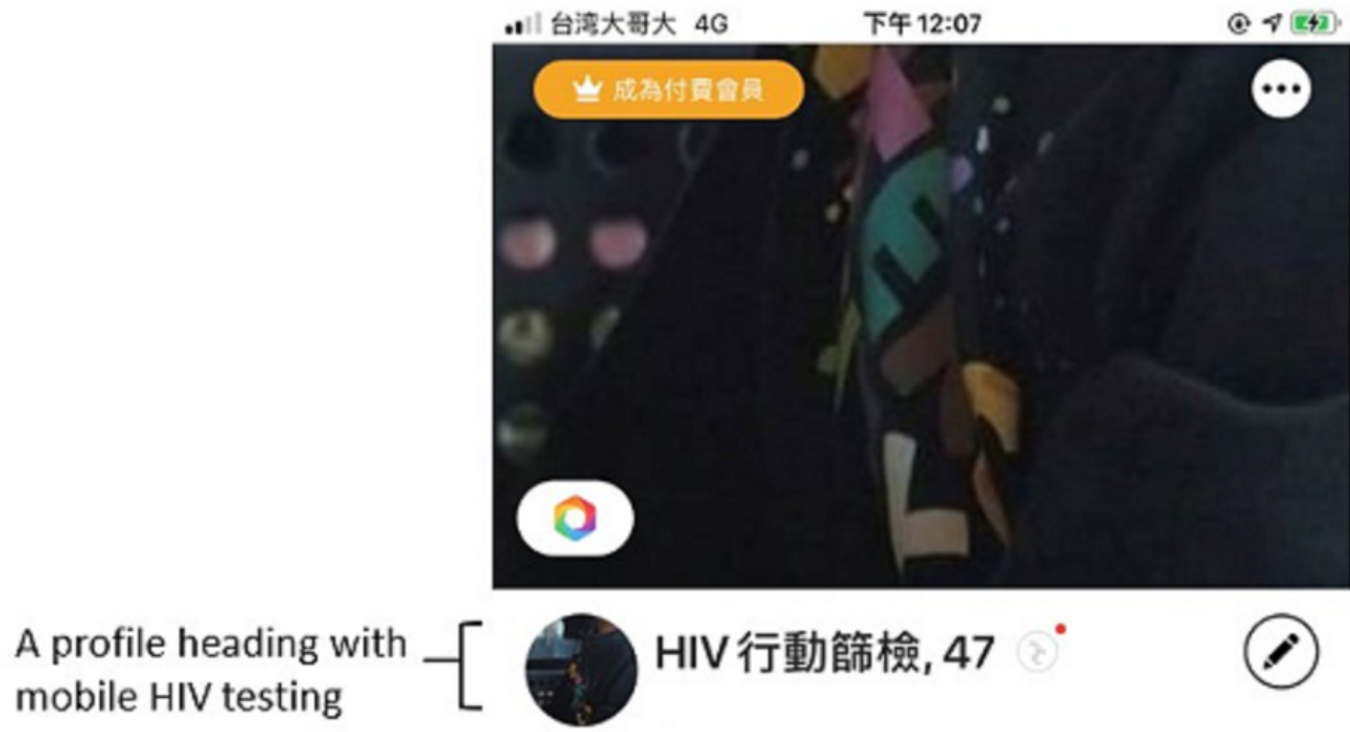

HIV 行動篩檢, 47

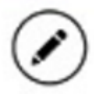

$\begin{array}{lll}2 & 1 & 0 \\ \text { 粉絲 } & \text { 追蹤中 } & \text { 貼文 }\end{array}$

Entrusted planning unit $-[$ 疾病管制罟委託計劃

Delivering a free, anonymous, and negotiable screening timeand place of HIV testing; the content of HIV
*縗 HIV 管檢零阻力

*立即線上傳訊預約您方便的時間與地點進行 HIV 快篩

*全程免費區名, 立刻知道结果

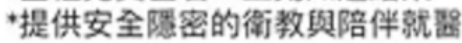

\section{其他預約與瞬絡管道}

FB@tpesafe1069

LINE@tym1056m

数迎主動詢問啫

\section{Q}

Figure 2. The profile of the mobile HIV testing on the Facebook page.

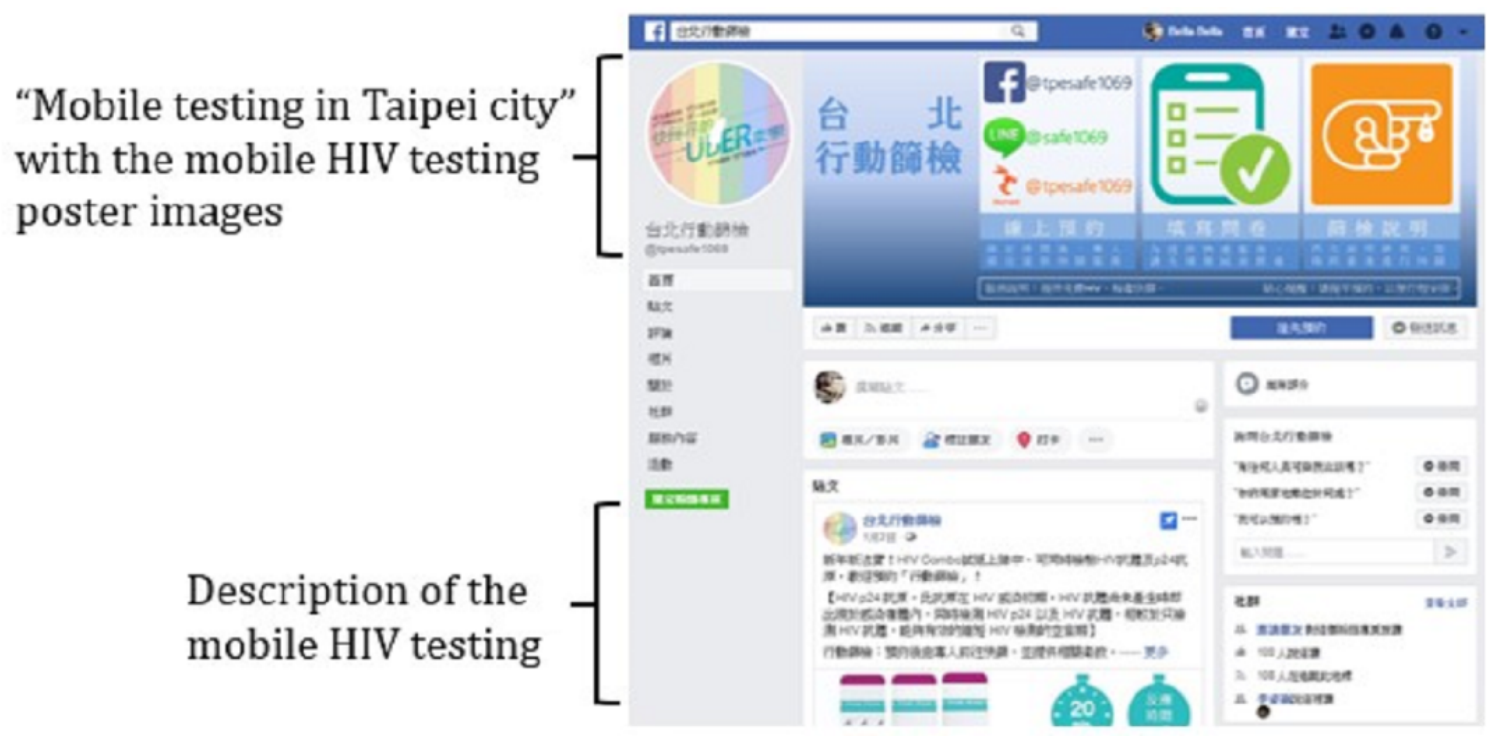


We encouraged the participants who had finished the mobile HIV testing to refer to their social network to make a mobile HIV testing appointment through a quick response code for a messenger app (Line app).

The same research assistant delivered the VCT according to the appointment at a designated time between $10 \mathrm{AM}$ to noon and
1:30 PM to 7:30 PM on weekdays and at a convenient place. The ensuing test counseling, testing procedures, and posttest services were the same as in the traditional VCT model.

Table 1 shows the content comparison of the 2 VCT models.

Table 1. The content comparison of the 2 voluntary counseling and testing models.

\begin{tabular}{|c|c|c|}
\hline Process & Traditional $\mathrm{VCT}^{\mathrm{a}}$ model & Social networking VCT model \\
\hline $\begin{array}{l}\text { The client mobiliza- } \\
\text { tion and recruitment } \\
\text { strategies }\end{array}$ & $\begin{array}{l}\text { - The screening information is announced through a } \\
\text { public website of a municipal hospital every day dur- } \\
\text { ing the research period } \\
\text { - Subjects pass and see the outreach station } \\
\text { - } \quad \text { Referral by their networks }\end{array}$ & 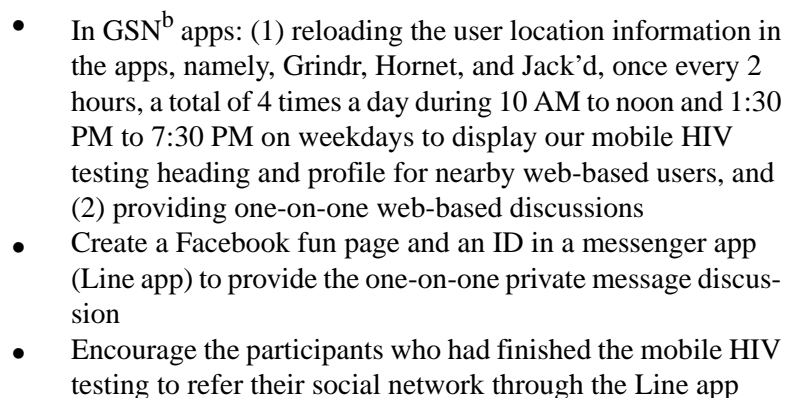 \\
\hline
\end{tabular}

Time of VCT 6 PM to 10 PM every Friday and Saturday

Location of VCT An outreach screening station at an entrance of the largest gay village in Taipei City

Testing appointment No need to make an appointment

Testing method Rapid HIV test

Staff A trained research assistant

Result notification Informed of the HIV testing result immediately after the test

Posttest services
The referring of confirm test and $\mathrm{PEP}^{\mathrm{c}}$ and $\operatorname{PrEP}^{\mathrm{d}}$ can be arranged directly according to the testing result
Designated by the participants during $10 \mathrm{AM}$ to noon and 1:30 PM to 7:30 PM every weekday

Designated by the participants at a convenient place in Taipei and New Taipei City

Need to make an appointment

Rapid HIV test

A trained research assistant

Informed of the HIV testing result immediately after the test

The referring of confirm test and PEP and PrEP can be arranged directly according to the testing result

${ }^{\mathrm{a} V C T}$ : voluntary counseling and testing.

${ }^{\mathrm{b}} \mathrm{GSN}$ : geosocial network.

${ }^{\mathrm{c}} \mathrm{PEP}$ : postexposure prophylaxis.

${ }^{\mathrm{d}}$ PrEP: pre-exposure prophylaxis.

\section{Instrument}

\section{Demographic Characteristics Questionnaire}

Participants provided demographic information, such as age, education, employment status, religion, and whether coming out of sexual orientation.

\section{HIV Risk-Taking Behaviors Questionnaire}

HIV risk-taking behaviors included days since the last unsafe sex, seeking sexual activity through social media, the nature of the relationship with the current sexual partner within the past 3 months, the frequency of anal intercourse and of condom use during anal intercourse within the past 3 months, recreational drug use, history of sexually transmitted diseases, having had a prior HIV test, regularity of this testing within the previous year, and previous PEP and PrEP.

\section{Rapid HIV Test}

DETERMINE HIV-1 and 2, antigen and antibody combo was used as the rapid screening tool in this study, which was licensed by the Taiwan Food and Drug Administration with a high sensitivity of $100 \%$ and a high specificity of $99.5 \%$ [32]. It takes only about $15 \mathrm{~min}$ to obtain the results, and it can be performed by trained staff.

\section{Propensity Score Matching and Multivariable Statistical Analyses}

As the subjects who accepted the anonymous HIV testing could not be randomly assigned, propensity score matching (PSM) was applied using SPSS (SPSS Inc.) software to perform the matching in a $1: 1$ ratio with a caliper distance of 0.001 between the 2 VCT models to control the extraneous variables and improve the homogeneity of the characteristics of the participants in the 2 VCT models. Perfect PSM was based on age, education, and employment level [33]. The comparison of demographic data and risk-taking behavior (secondary outcome) between the 2 models was analyzed using a paired $t$ test for continuous variables and a chi-square test for categorical variables. Percentages were used to describe the distribution of the time and location of the social networking VCT model. All 
testing locations were imported into Google Maps to calculate the coverage area of the social networking VCT model. The incidence rate ratio (IRR) and 95\% CI were used to test the significance of the primary outcome of HIV testing results and the referral rates after a positive result.

\section{Estimation of Sample Size}

$\mathrm{G}^{*}$ Power was used to estimate the matched pair sample size. On the basis of an effect size of 0.25 and power of 0.95 , the sample size in each group was calculated to be 175 . At a loss rate of $20 \%$, the sample size was calculated to be at least 210 for each group.

\section{Results}

\section{The Recruitment and Completion of 2 VCT Models}

Figure 3 shows the attrition diagrams of the 2 VCT models. In total, $831 \mathrm{MSM}$ participants were recruited into the $2 \mathrm{VCT}$ models during the research period: 215 in the social networking VCT model and 616 in the traditional VCT model. An estimated 7200 visits, including website browsing, passing, or referrals for obtaining the VCT in the outreach station, achieved a completion rate of $8.56 \%(616 / 7200)$ in the traditional VCT model. Of the 215 participants in the social networking VCT model, $73.5 \%$ (158) were recruited via GSN apps, $16.7 \%$ (36) were recruited via the Line app, and $9.8 \%$ (21) were recruited via the FB fun page. A total of 845 GSN app users in Grindr, Hornet, and Jack'd actively gave us a tap, of which $35.4 \%$ (299) entered a one-on-one web-based discussion with the research assistant and 52.8\% (158/299) received the VCT. After 48 private message discussions from 128 viewers through FB fun page, $44 \%$ (21/48) users received the VCT. There were 65 referred users sending the message to as through Line app, of which $92 \%$ (60) of them had one-on-one web-based discussion and $60 \%(36 / 60)$ of those received the VCT. The overall completion rate of the social networking VCT model, which was calculated through the number of the participants who have completed the mobile HIV testing $(n=215)$ divided by the sum of number of the subjects who giving as the tap in GSN app $(n=845)$, being viewers in the FB fun page $(n=128)$, and being referred through the Line app $(n=65)$, the result is $20.71 \%$ $(215 / 1038)$. The main reasons for not accepting social networking VCT include having no response message, having been screened recently, having no risk-taking behavior, and not wanting to know the result.

Figure 3. Attrition diagram for the 2 voluntary counseling and testing models. GSN: geosocial network; VCT: voluntary counseling and testing.

Traditional VCT model

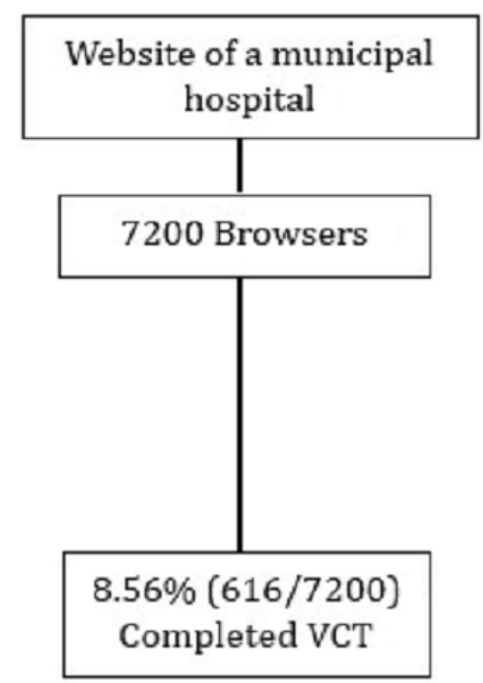

The most popular designated testing period of the social networking VCT model was 1:30 PM to 5:30 PM (129/215, $60.0 \%)$, followed by $10 \mathrm{AM}$ to noon $(48 / 215,22.3 \%)$ and $5: 30$ $\mathrm{PM}$ to $7: 30 \mathrm{PM}(38 / 215,17.7 \%)$. The testing locations of the social networking VCT model and reloading locations of GSN apps by mobile phones expanded to adjacent walking areas within the 55 Taipei mass rapid transportation (MRT) stations (Figure 4). The total area of the social networking VCT model was calculated after connecting the farthest MRT station and was estimated to be $235.28 \mathrm{~km}^{2}$, which covered $10.12 \%$ of the
Social networking VCT model

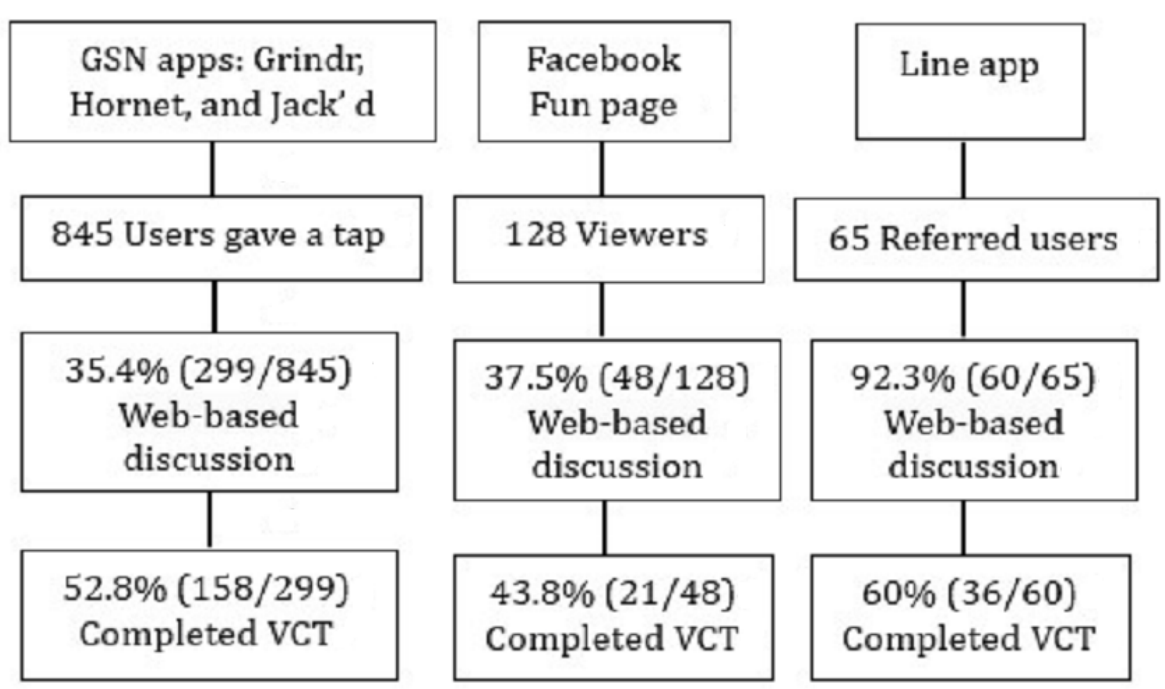

area of Taipei and New Taipei City. Figure 4 also shows the distribution of screening numbers for MSM. There were $29.3 \%$ (63/215) participants who requested mobile HIV testing of the social networking VCT model at their own house, $27.0 \%$ $(58 / 215)$ at a convenience store such as 7-Eleven or Family Mart, and 24.2\% (52/215) at a fast-food restaurant or café such as McDonalds or Starbucks. There were $14.0 \%$ (30/215) participants who requested mobile HIV testing in an outdoor area, such as a street side, a garden, or a school campus corner, and $5.6 \%(12 / 215)$ at a gay bar. 
Figure 4. The distribution of tested men who have sex with men in social networking voluntary counseling and testing model in Taipei and New Taipei City.

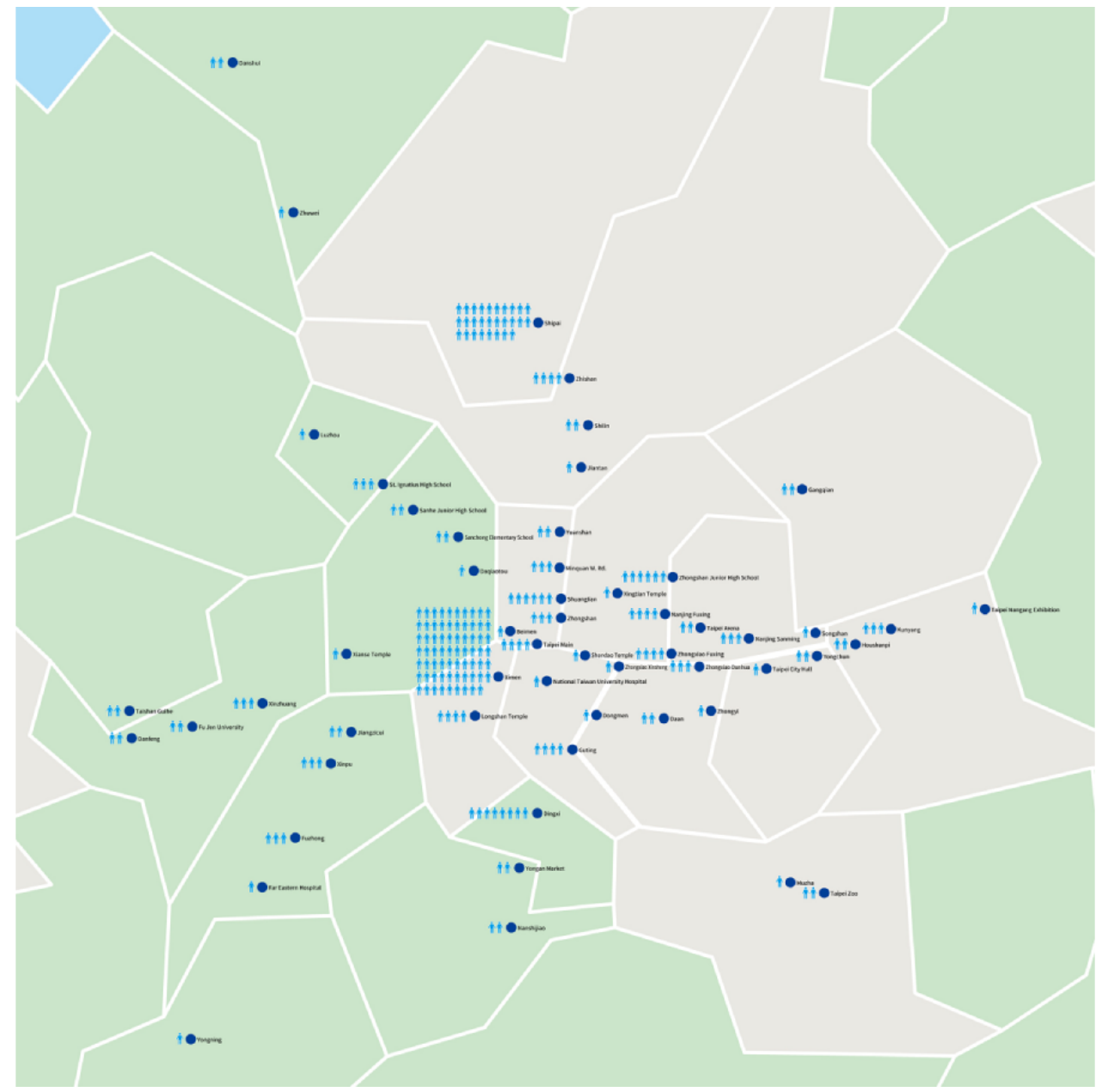

\section{The Comparison of the Characteristics of MSM Between the 2 VCT Models}

After PSM, 215 participants with a perfect match score were selected for each model. Table 2 presents a comparison of the participants' characteristics between the 2 models. The mean age of all participants was 29.97 years (SD 7.61); most had college- or university-level education (294/430, 68.4\%), were employed (296/430,68.8\%), and did not practice any religion $(224 / 430,52.1 \%)$. Approximately $60.5 \%(260 / 430)$ of the participants responded that they had experience coming out as MSM. After PSM, the demographic characteristics analysis results showed homogeneity between the 2 groups. 
Table 2. The comparison of the characteristics of men who have sex with men between 2 voluntary counseling and testing models.

\begin{tabular}{|c|c|c|c|c|c|c|c|c|c|}
\hline \multirow[t]{2}{*}{ Variable } & \multicolumn{2}{|c|}{ Total $(\mathrm{N}=430)$} & \multicolumn{2}{|c|}{$\begin{array}{l}\text { Traditional } \mathrm{VCT}^{\mathrm{a}} \text { model } \\
(\mathrm{n}=215)\end{array}$} & \multicolumn{2}{|c|}{$\begin{array}{l}\text { Social networking VCT } \\
\text { model }(n=215)\end{array}$} & \multirow[t]{2}{*}{$t$ test $(d f)$} & \multirow{2}{*}{$\begin{array}{l}\text { Chi- } \\
\text { square } \\
(d f)\end{array}$} & \multirow[t]{2}{*}{$P$ value } \\
\hline & Mean (SD) & $\mathrm{n}(\%)$ & $\begin{array}{l}\text { Mean } \\
(\mathrm{SD})\end{array}$ & $\mathrm{n}(\%)$ & $\begin{array}{l}\text { Mean } \\
(\mathrm{SD})\end{array}$ & $\mathrm{n}(\%)$ & & & \\
\hline Age (years) & $29.97(7.61)$ & $N / A^{b}$ & $30.03(7.8)$ & N/A & $29.79(7.5)$ & N/A & $\begin{array}{l}-0.39 \\
(214)\end{array}$ & N/A & .70 \\
\hline Education & & & & & & & N/A & $0.0(2)$ & $>.99$ \\
\hline Above university & N/A & $86(20.0)$ & N/A & $43(20.0)$ & N/A & $43(20.0)$ & & & \\
\hline College or university & N/A & $294(68.4)$ & N/A & 147 (68.4) & N/A & 147 (68.4) & & & \\
\hline High school or less & N/A & $50(11.6)$ & N/A & $25(11.6)$ & N/A & $25(11.6)$ & & & \\
\hline Employment status & & & & & & & N/A & $0.0(2)$ & $>.99$ \\
\hline Student & N/A & $92(21.4)$ & N/A & $46(21.4)$ & N/A & $46(21.4)$ & & & \\
\hline Employed & N/A & $296(68.8)$ & N/A & $148(68.8)$ & N/A & $148(68.8)$ & & & \\
\hline Unemployed & N/A & $42(9.8)$ & N/A & $21(9.8)$ & N/A & $21(9.8)$ & & & \\
\hline Religion & & & & & & & N/A & $0.2(1)$ & .70 \\
\hline Yes & N/A & $206(47.9)$ & N/A & $101(47.0)$ & N/A & 105 (48.8) & & & \\
\hline No & N/A & $224(52.1)$ & N/A & $114(53.0)$ & N/A & $110(51.2)$ & & & \\
\hline Coming out of sexual or & entation & & & & & & N/A & $0.97(1)$ & .32 \\
\hline Yes & N/A & $260(60.5)$ & N/A & $125(58.1)$ & N/A & $135(62.8)$ & & & \\
\hline No & N/A & $170(39.5)$ & N/A & $90(41.9)$ & N/A & $80(37.2)$ & & & \\
\hline
\end{tabular}

${ }^{\mathrm{a} V C T}$ : voluntary counseling and testing.

${ }^{\mathrm{b}} \mathrm{N} / \mathrm{A}$ : not applicable.

\section{The Comparison of the Risk-Taking Behavior of MSM Between the 2 VCT Models}

Compared with the traditional VCT model, some of the HIV risk-taking behaviors were significantly higher in the social networking VCT model (Table 3). The last unsafe sex time to date (in days) was 79.89 days shorter $\left(\mathrm{t}_{209}=-12.16 ; P<.001\right)$ in the social networking VCT model than in the traditional VCT model. There were $9.8 \%\left(21 / 215 ; \chi^{2}{ }_{1}=5.7 ; P=.02\right)$ more participants in the social networking VCT model who had experience seeking sex through social media as compared with the traditional VCT model. The percentage of participants having multiple relationships with current sexual partners within the past 3 months in the social networking VCT model was $17.7 \%$ (38/215) more and significantly higher than the traditional VCT model $\left(\chi_{1}^{2}=14.5 ; P=.001\right)$. The mean number of anal intercourses within the past 3 months was 1.95 times significantly higher in the social networking VCT model than in the traditional VCT model $\left(\mathrm{t}_{213}=3.2 ; P=.002\right)$. The social networking VCT model participants reported 10.2\% (22/215) more of not using a condom every time and 3.3\% (7/215) more of never used a condom during anal intercourse within the past 3 months, compared with the traditional VCT model participants $\left(\chi_{2}^{2}=8.8 ; P=.01\right)$. The experience of recreational drug use was $15.3 \%(33 / 215)$ more and was significantly higher among participants in the social networking VCT model than among those in the traditional VCT model $\left(\chi_{1}^{2}=16.6 ; P<.001\right)$. In total, $13.5 \%(29 / 215)$ more of the social networking VCT model participants reported having a history of a sexually transmitted disease, as compared with the traditional VCT model participants $\left(\chi_{1}^{2}=11.7 ; P=.001\right)$. There were $7.0 \%(15 / 215$; $\left.\chi_{1}^{2}=4.7 ; P=.03\right)$ and $8.8 \%\left(19 / 215 ; \chi^{2}{ }_{1}=7.1 ; P=.008\right)$ more of participants in the social networking VCT model who did not undergo HIV testing or regularly receive testing, respectively, than those in the traditional VCT model. There were no significant differences in the percentage of patients with PEP and PrEP between the two VCT models. 
Table 3. The comparison of the risk-taking behavior of men who have sex with men between two voluntary counseling and testing models.

\begin{tabular}{|c|c|c|c|c|c|c|c|c|c|}
\hline \multirow[t]{2}{*}{ Variable } & \multicolumn{2}{|c|}{ Total $(\mathrm{N}=430)$} & \multicolumn{2}{|c|}{$\begin{array}{l}\text { Traditional } \mathrm{VCT}^{\mathrm{a}} \text { model } \\
(\mathrm{n}=215)\end{array}$} & \multicolumn{2}{|c|}{$\begin{array}{l}\text { Social networking VCT } \\
\text { model }(\mathrm{n}=215)\end{array}$} & \multirow[t]{2}{*}{$t$ test $(d f)$} & \multirow[t]{2}{*}{$\begin{array}{l}\text { Chi-square } \\
(d f)\end{array}$} & \multirow[t]{2}{*}{$P$ value } \\
\hline & Mean (SD) & $\mathrm{n}(\%)$ & Mean (SD) & $\mathrm{n}(\%)$ & Mean (SD) & $\mathrm{n}(\%)$ & & & \\
\hline Days since the last unsafe sex & $\begin{array}{l}65.2 \\
(76.52)\end{array}$ & $\mathrm{N} / \mathrm{A}^{\mathrm{b}}$ & $\begin{array}{l}107.8 \\
(84.71)\end{array}$ & N/A & $\begin{array}{l}27.91 \\
(37.59)\end{array}$ & N/A & $\begin{array}{l}-12.2 \\
(209)\end{array}$ & N/A & $<.001$ \\
\hline \multicolumn{7}{|c|}{ Seeking sexual activity through social media } & N/A & $5.7(1)$ & .02 \\
\hline Yes & N/A & $329(76.5)$ & N/A & $154(71.6)$ & N/A & $175(81.4)$ & & & \\
\hline No & N/A & $101(23.5)$ & N/A & $61(28.4)$ & N/A & $40(18.6)$ & & & \\
\hline \multicolumn{7}{|c|}{ Relationship with the current sexual partner ${ }^{c}$} & N/A & $14.5(2)$ & .001 \\
\hline Only one and stable & N/A & $149(34.7)$ & N/A & $89(41.1)$ & N/A & $60(27.9)$ & & & \\
\hline Multiple & N/A & $180(41.9)$ & N/A & $71(33.0)$ & N/A & $109(50.7)$ & & & \\
\hline Single & N/A & $101(23.5)$ & N/A & $55(25.6)$ & N/A & $46(21.4)$ & & & \\
\hline Number of anal intercourses ${ }^{c}$ & $5.00(6.83)$ & N/A & $3.94(4.24)$ & N/A & $5.89(8.39)$ & N/A & $3.2(213)$ & N/A & .002 \\
\hline \multicolumn{7}{|c|}{ Condom use frequency during anal intercourse ${ }^{c}$} & N/A & $8.8(2)$ & .01 \\
\hline Every time used & N/A & $165(38.4)$ & N/A & $97(45.1)$ & N/A & $68(31.6)$ & & & \\
\hline Not every time used & N/A & $236(54.9)$ & N/A & $107(49.8)$ & N/A & $129(60.0)$ & & & \\
\hline Never used & N/A & $29(6.7)$ & N/A & $11(5.1)$ & N/A & $18(8.4)$ & & & \\
\hline \multicolumn{7}{|c|}{ Experience of recreational drug use } & N/A & $16.6(1)$ & $<.001$ \\
\hline Yes & N/A & $81(18.8)$ & N/A & $24(11.2)$ & N/A & $57(26.5)$ & & & \\
\hline No & N/A & $349(81.2)$ & N/A & $191(88.8)$ & N/A & $158(73.5)$ & & & \\
\hline \multicolumn{7}{|c|}{ History of sexual transmitted disease } & N/A & $11.7(1)$ & .001 \\
\hline Yes & N/A & $91(21.2)$ & N/A & $31(14.4)$ & N/A & $60(27.9)$ & & & \\
\hline No & N/A & $339(78.8)$ & N/A & $184(85.6)$ & N/A & $155(72.1)$ & & & \\
\hline \multicolumn{7}{|l|}{ Having had a prior HIV test } & N/A & $4.7(1)$ & .03 \\
\hline Yes & N/A & $375(87.2)$ & N/A & $195(90.7)$ & N/A & $180(83.7)$ & & & \\
\hline No & N/A & $55(12.8)$ & N/A & $20(9.3)$ & N/A & $35(16.3)$ & & & \\
\hline \multicolumn{7}{|c|}{ Having HIV test regularly $(n=375)^{d}$} & N/A & $7.1(1)$ & .008 \\
\hline Yes & N/A & $268(71.5)$ & N/A & $151(77.4)$ & N/A & $117(65.0)$ & & & \\
\hline No & N/A & $107(28.5)$ & N/A & $44(22.6)$ & N/A & $63(35.0)$ & & & \\
\hline \multicolumn{7}{|l|}{ Having $\operatorname{PEP}^{\mathrm{e}}$ previously } & N/A & $2.7(1)$ & .10 \\
\hline Yes & N/A & $33(7.7)$ & N/A & $12(5.6)$ & N/A & $21(9.8)$ & & & \\
\hline No & N/A & 397 (92.3) & N/A & 203 (94.4) & N/A & $194(90.2)$ & & & \\
\hline \multicolumn{7}{|l|}{ Having $\operatorname{PrEP}^{\mathrm{f}}$ previously } & N/A & $1.8(1)$ & .18 \\
\hline Yes & N/A & $40(9.3)$ & N/A & $16(7.4)$ & N/A & $24(11.2)$ & & & \\
\hline No & N/A & $390(90.7)$ & N/A & 199 (92.6) & N/A & $191(88.8)$ & & & \\
\hline
\end{tabular}

${ }^{\mathrm{a}} \mathrm{VCT}$ : voluntary counseling and testing.

${ }^{\mathrm{b}} \mathrm{N} / \mathrm{A}$ : not applicable.

${ }^{\mathrm{c}}$ Within the past 3 months.

${ }^{\mathrm{d}}$ Within the past 1 year.

${ }^{\text {e}}$ PEP: postexposure prophylaxis.

${ }^{\mathrm{f}} \mathrm{PrEP}$ : pre-exposure prophylaxis. 


\section{Comparison of the HIV Case Finding and Clinic Referrals of the 2 VCT Models}

Table 4 compares HIV testing and referrals to the clinic results between the two models. The HIV positive rate was significantly higher in the social networking VCT model $(13 / 215,6.0 \%)$ than in the traditional VCT model $(4 / 215,1.9 \%$; IRR $3.40,95 \%$ CI $1.089-10.584 ; P=.03)$. The referral rate to the clinics for confirmation diagnosis and treatment after an HIV positive result was significantly higher in the social networking VCT model $(12 / 13,92 \%)$ than in the traditional VCT model $(1 / 4$, 25\%) (IRR 0.03, 95\% CI 0.001-0.585; $P=.006$ ).

Table 4. The comparison of the HIV case finding and clinic referrals between the 2 voluntary counseling and testing models

\begin{tabular}{|c|c|c|c|c|c|}
\hline Variable & $\begin{array}{l}\text { Traditional VCT } \mathrm{V}^{\mathrm{a}} \text { model } \\
(\mathrm{n}=215), \mathrm{n}(\%)\end{array}$ & $\begin{array}{l}\text { Social networking VCT } \\
\text { model }(\mathrm{n}=215), \mathrm{n}(\%)\end{array}$ & $\mathrm{IRR}^{\mathrm{b}, \mathrm{c}}$ & $95 \% \mathrm{CI}$ & $P$ value \\
\hline HIV positive & $4(1.9)$ & $13(6.0)$ & 3.40 & $1.089-10.584$ & .03 \\
\hline $\begin{array}{l}\text { Referred to the clinics for confirmation, diag- } \\
\text { nosis, and treatment }\end{array}$ & $1(25.0)$ & $12(92.3)$ & 0.03 & $0.001-0.585$ & .006 \\
\hline
\end{tabular}

${ }^{\mathrm{a}} \mathrm{VCT}$ : voluntary counseling and testing.

${ }^{\mathrm{b}}$ IRR: incidence rate ratio.

${ }^{\mathrm{c}}$ Incidence rate ratio was used to compare the difference of ratio.

\section{Discussion}

\section{Principal Findings}

This study applied mobile HIV testing via recruitment from social networking platforms and measured HIV case finding results. The two main findings were as follows: (1) compared with those receiving the traditional VCT model, the social networking VCT model of mobile HIV testing is more likely to reach MSM who have higher HIV risk-taking behaviors and (2) the HIV positive rates are 3 times significantly higher among those receiving the social networking VCT model than the traditional VCT model. There are three possible reasons why the HIV positive rate is higher in the social networking VCT model than in the traditional VCT model.

First, reloading into popular GSN apps in different locations could effectively enlarge the areas exposed to information about HIV testing to web-based MSM. As compared with the traditional VCT model, which provides public testing information on a certain website, the social networking VCT model was applied through the most popular GSN apps used by MSM $[12,34,35]$. Previous studies have indicated that MSM on social networking platforms also engage in more active unsafe sexual behaviors and do not regularly test for HIV [11-13,15-18,36]. The active presentation of heading and profiles in the social networking VCT model for nearby web-based users periodically and substantially increased mobile HIV testing information dissemination to high risk-taking MSM. Due to the delivery of VCT to the participant, the research assistant reloaded into GSN apps at an additional 55 locations, which increased the opportunity to reach broader web-based audiences [37] and avoided repeated recruitment [31]. In previous studies, pop-up and banner-paid advertisements and message sending were used to recruit MSM through GSN apps, and the range of the click-through rate was between $2.8 \%$ and $61.3 \%$ within 6 weeks to 4 months [12,22,38]. In our study, 4 times per day and a total of 1440 times of reloading into 3 GSN apps within 6 months without charge aroused 845 web-based users to click-tap, giving a click-through rate of $58.9 \%$, which has the same effect of drawing attention as the paid advertisement. The reloading strategy of GSN apps with an attractive heading and profile of mobile HIV testing could successfully promote the attention and engagement of the research among nearby web-based MSM users, who had higher rates of HIV risk-taking behaviors.

Second, testing behavior was promoted through interactive and private message-based discussions of HIV risk-taking assessment through social networking platforms and flexible testing protocols. The HIV testing behavior of MSM could be motivated through the interactive and stimulating web-based counseling about risk-taking awareness and testing resources $[23,39,40]$ and offering a flexible time and location for HIV screening to meet the participants' needs [41]. In our study, the average completion rate of the social networking VCT model after a one-on-one discussion with web-based users was $20.8 \%$, which is higher than that of the traditional VCT model $(8.56 \%)$. The client's own house was the most preferred place for the participants in the social networking VCT model because of privacy and convenience [42]. Although no injurious event was reported while providing the mobile HIV testing at clients' homes, it is worth noting that safety procedures were in place before going to the designated location. These included informing the team member of the time and place, setting up an emergency call button on the home page of the cell phone, and, if there were possible dangers during the test, arranging for a colleague to accompany the service provider as necessary. Compared with previous studies that applied the mobile HIV testing in a specific shelter and trunk [8-10], this study found that the mobile HIV testing could be conducted in a daily life environment, such as the seating area of convenience stores and restaurants around an MRT station in Taiwan.

Third, referrals were made via the risk-taking sexual network by those participants who had completed the mobile HIV testing of the social networking VCT model through the convenience of the Line app. MSM undergoing HIV testing usually self-identify as being exposed to risk-taking sexual behaviors and/or many sexual partners $[43,44]$. The acquisition of HIV testing information through network-mediated MSM could significantly predict more HIV testing behaviors than other models [45]. In addition to encouraging the sharing of HIV 
testing information to the network of those who had finished the social networking VCT model, we also provided a convenient referral link by using the quick response code of the Line app. Referral of those MSM with HIV risk-taking could be facilitated while applying the information linking function and immediate web-based discussion within the Line app.

Higher referral rates to the clinic after testing HIV positive in the social networking VCT model than the traditional VCT model may be attributed to the fact that the social networking VCT model could be arranged during the daytime, providing enough time for the research assistant to accompany the positive participants immediately to the hospital for a confirmation test and further treatment. Moreover, 6.0\% (12/199) of the HIV-negative participants in the social networking VCT model were referred to the PEP or PrEP clinic by our research assistant, which is higher than the traditional VCT model that had no referrals to the PEP or PrEP. The flexible HIV testing algorithms increased the chance of accessing treatment after an HIV-positive result and being given information regarding preventive measures after HIV-negative results [46].

\section{Limitations}

This study has several limitations that need to be addressed. First, the sources of the recruited participants were mainly Taipei and New Taipei City, which is a metropolitan area with convenient transportation that may limit the generalizability and extension of the results to rural areas. Second, self-report questionnaires may be skewed toward social desirability and could influence the validity of the results. Third, the implementation methods differed in several aspects between the two VCT models. These included client mobilization, recruitment methods, and testing schedules. Therefore, the effects of the social networking VCT model on HIV case findings are unclear. Fourth, the design and methods of this study require well-trained full-time personnel. Therefore, it is difficult to perform the social networking VCT model in a real-world setting when human resources and budgets are in shortage.

\section{Conclusions}

Compared with the traditional VCT model, the social networking VCT model could successfully recruit web-based MSM with a higher risk-taking of HIV by periodically reloading into social networking platforms and having discussions. The VCT is delivered in flexible testing times and locations, which increases the motivation for HIV testing behavior. Referrals to the clinic for the confirmation of diagnosis and treatment, and for PEP or PrEP, are also feasible after the social networking VCT model. The cost-effectiveness and more rigorous design of the social networking VCT model could be assessed in the future to evaluate the outcomes and increase clinical receptivity.

\section{Acknowledgments}

The authors would like to thank the Centers for Disease Control, Taiwan, ROC (MOHW107-Cover Page CDC-C-114-000106) for providing research funding. The authors are grateful to the gay bars that provide a place for the traditional VCT model. The authors are also grateful to the municipal hospital that provided HIV testing resources.

\section{Conflicts of Interest}

There are no competing financial interests in this research. The purpose of the research did not reflect the official policy or position of the organization or government.

\section{References}

1. Understanding fast-track: Accelerating action to end the AIDS epidemic by 2030. Joint United Nations Programme on HIV and AIDS. 2021. URL: https://www.unaids.org/sites/default/files/media asset/201506 JC2743 Understanding FastTrack en. pdf

2. The 2020 HIV Self-Screening Program is launched! Regular screening for peace of mind. Centers for Disease Control, Taiwan. 2020 May 01. URL: https://www.cdc.gov.tw/Bulletin/Detail/P7tQd645gMwWVa8jCDkJ Q?typeid=9 [accessed 2020-06-08]

3. AIDS statistics data. Centers for Disease Control, Taiwan. 2021 Jan 31. URL: https://www.cdc.gov.tw/Category/Page/ rCV9N1rGUz9wNr81ggsh2Q [accessed 2019-09-21]

4. Joint UNPOHIVAIDS. 2020. URL: https://www.unaids.org/en/resources/fact-sheet [accessed 2020-10-21]

5. Bowles KE, Clark HA, Tai E, Sullivan PS, Song B, Tsang J, et al. Implementing rapid HIV testing in outreach and community settings: results from an advancing HIV prevention demonstration project conducted in seven U.S. cities. Public Health Rep 2008;123 Suppl 3(1):78-85 [FREE Full text] [doi: 10.1177/00333549081230S310] [Medline: 19172705]

6. Scognamiglio P, Chiaradia G, Giovanetti M, Albertini E, Camposeragna A, Farinella M, et al. HIV rapid testing in community and outreach sites: results of a nationwide demonstration project in Italy. BMC Public Health 2018 Jun 18;18(1):748 [FREE Full text] [doi: 10.1186/s12889-018-5680-6] [Medline: 29914449]

7. Bassett IV, Regan S, Luthuli P, Mbonambi H, Bearnot B, Pendleton A, et al. Linkage to care following community-based mobile HIV testing compared with clinic-based testing in Umlazi Township, Durban, South Africa. HIV Med 2014 Jul;15(6):367-372 [FREE Full text] [doi: 10.1111/hiv.12115] [Medline: 24251725]

8. Grabbe KL, Menzies N, Taegtmeyer M, Emukule G, Angala P, Mwega I, et al. Increasing access to HIV counseling and testing through mobile services in Kenya: strategies, utilization, and cost-effectiveness. J Acquir Immune Defic Syndr 2010 Jul;54(3):317-323 [FREE Full text] [doi: 10.1097/QAI.0b013e3181ced126] [Medline: 20453819] 
9. Mabuto T, Latka MH, Kuwane B, Churchyard GJ, Charalambous S, Hoffmann CJ. Four models of HIV counseling and testing: utilization and test results in South Africa. PLoS One 2014;9(7):e102267 [FREE Full text] [doi: 10.1371/journal.pone.0102267] [Medline: 25013938]

10. Meehan S, Naidoo P, Claassens MM, Lombard C, Beyers N. Characteristics of clients who access mobile compared to clinic HIV counselling and testing services: a matched study from Cape Town, South Africa. BMC Health Serv Res 2014 Dec 20;14:658 [FREE Full text] [doi: 10.1186/s12913-014-0658-2] [Medline: 25526815]

11. Beymer MR, Rossi AD, Shu SB. Assessing Self-Control and Geosocial Networking App Behavior Among an Online Sample of Men Who Have Sex with Men. J Urban Health 2016 Aug;93(4):698-708 [FREE Full text] [doi: 10.1007/s11524-016-0056-7] [Medline: 27184573]

12. Holloway IW, Rice E, Gibbs J, Winetrobe H, Dunlap S, Rhoades H. Acceptability of smartphone application-based HIV prevention among young men who have sex with men. AIDS Behav 2014 Feb;18(2):285-296 [FREE Full text] [doi: 10.1007/s10461-013-0671-1] [Medline: 24292281]

13. Ko NY, Tseng PC, Huang YC, Chen YC, Hsu ST. Seeking sex partners through the internet and mobile phone applications among men who have sex with men in Taiwan. AIDS Care 2016 Jul;28(7):927-931. [doi: 10.1080/09540121.2015.1131969] [Medline: 26754350]

14. Chan PA, Towey C, Poceta J, Rose J, Bertrand T, Kantor R, et al. Online hookup sites for meeting sexual partners among men who have sex with men in Rhode Island, 2013: a call for public health action. Public Health Rep 2016;131(2):264-271 [FREE Full text] [doi: 10.1177/003335491613100210] [Medline: 26957661]

15. Landovitz RJ, Tseng CH, Weissman M, Haymer M, Mendenhall B, Rogers K, et al. Epidemiology, sexual risk behavior, and HIV prevention practices of men who have sex with men using GRINDR in Los Angeles, California. J Urban Health 2013 Aug;90(4):729-739 [FREE Full text] [doi: 10.1007/s11524-012-9766-7] [Medline: 22983721]

16. Lehmiller JJ, Ioerger M. Social networking smartphone applications and sexual health outcomes among men who have sex with men. PLoS One 2014;9(1):e86603 [FREE Full text] [doi: 10.1371/journal.pone.0086603] [Medline: 24466166]

17. O'Connor L, O'Donnell K, Barrett P, Hickson FCI, McCartney D, Quinlan M, et al. Use of geosocial networking applications is independently associated with diagnosis of STI among men who have sex with men testing for STIs: findings from the cross-sectional MSM Internet Survey Ireland (MISI) 2015. Sex Transm Infect 2019 Jun;95(4):279-284 [FREE Full text] [doi: 10.1136/sextrans-2018-053637] [Medline: $\underline{\text { 30518621] }}$

18. Chow EP, Cornelisse VJ, Read TR, Hocking JS, Walker S, Chen MY, et al. Risk Practices in the Era of Smartphone Apps for Meeting Partners: A Cross-Sectional Study Among Men Who Have Sex with Men in Melbourne, Australia. AIDS Patient Care STDS 2016 Apr;30(4):151-154. [doi: 10.1089/apc.2015.0344] [Medline: 27028181]

19. Rendina HJ, Jimenez RH, Grov C, Ventuneac A, Parsons JT. Patterns of lifetime and recent HIV testing among men who have sex with men in New York City who use Grindr. AIDS Behav 2014 Jan;18(1):41-49 [FREE Full text] [doi: 10.1007/s10461-013-0573-2] [Medline: 23925515]

20. Sun CJ, Sutfin E, Bachmann LH, Stowers J, Rhodes SD. Comparing men who have sex with men and transgender women who use Grindr, other similar social and sexual networking apps, or no social and sexual networking apps: Implications for recruitment and health promotion. J AIDS Clin Res 2018;9(2) [FREE Full text] [doi: 10.4172/2155-6113.1000757] [Medline: 29593933]

21. Young SD, Cumberland WG, Nianogo R, Menacho LA, Galea JT, Coates T. The HOPE social media intervention for global HIV prevention in Peru: a cluster randomised controlled trial. Lancet HIV 2015 Jan;2(1):e27-e32 [FREE Full text] [doi: 10.1016/S2352-3018(14)00006-X] [Medline: 26236767]

22. Huang E, Marlin RW, Young SD, Medline A, Klausner JD. Using grindr, a smartphone social-networking application, to increase HIV self-testing among black and latino men who have sex with men in Los Angeles, 2014. AIDS Educ Prev 2016 Aug;28(4):341-350. [doi: 10.1521/aeap.2016.28.4.341] [Medline: 27427928]

23. Ko NY, Hsieh CH, Wang MC, Lee C, Chen CL, Chung AC, et al. Effects of Internet popular opinion leaders (iPOL) among Internet-using men who have sex with men. J Med Internet Res 2013;15(2):e40 [FREE Full text] [doi: 10.2196/jmir.2264] [Medline: 23439583]

24. Roberts N, Holden J, Duck T, Kitchener S. Health promotion 'on steroids': the value of an experiential approach to promote rapid HIV testing in NSW, Australia. Public Health Res Pract 2015 Mar 30;25(2):e2521522 [FREE Full text] [doi: 10.17061/phrp2521522] [Medline: 25848740]

25. Tang W, Wei C, Cao B, Wu D, Li KT, Lu H, et al. Crowdsourcing to expand HIV testing among men who have sex with men in China: A closed cohort stepped wedge cluster randomized controlled trial. PLoS Med 2018 Aug;15(8):e1002645 [FREE Full text] [doi: 10.1371/journal.pmed.1002645] [Medline: 30153265]

26. Chamie G, Clark TD, Kabami J, Kadede K, Ssemmondo E, Steinfeld R, et al. A hybrid mobile approach for population-wide HIV testing in rural east Africa: an observational study. Lancet HIV 2016 Mar;3(3):e111-e119 [FREE Full text] [doi: 10.1016/S2352-3018(15)00251-9] [Medline: 26939734]

27. Han L, Wei C, Muessig KE, Bien CH, Meng G, Emch ME, et al. HIV test uptake among MSM in China: Implications for enhanced HIV test promotion campaigns among key populations. Glob Public Health 2017 Jan;12(1):31-44 [FREE Full text] [doi: 10.1080/17441692.2015.1134612] [Medline: 26785328] 
28. Gelinas L, Pierce R, Winkler S, Cohen IG, Lynch HF, Bierer BE. Using social media as a research recruitment tool: ethical issues and recommendations. Am J Bioeth 2017 Mar;17(3):3-14 [FREE Full text] [doi: 10.1080/15265161.2016.1276644] [Medline: 28207365]

29. Holloway IW. Substance use homophily among geosocial networking application using gay, bisexual, and other men who have sex with men. Arch Sex Behav 2015 Oct;44(7):1799-1811 [FREE Full text] [doi: 10.1007/s10508-015-0581-6] [Medline: 26216146]

30. Arigo D, Pagoto S, Carter-Harris L, Lillie SE, Nebeker C. Using social media for health research: methodological and ethical considerations for recruitment and intervention delivery. Digit Health 2018;4:2055207618771757 [FREE Full text] [doi: 10.1177/2055207618771757] [Medline: 29942634]

31. Iribarren SJ, Ghazzawi A, Sheinfil AZ, Frasca T, Brown W, Lopez-Rios J, et al. Mixed-method evaluation of social media-based tools and traditional strategies to recruit high-risk and hard-to-reach populations into an HIV prevention intervention study. AIDS Behav 2018 Jan;22(1):347-357 [FREE Full text] [doi: 10.1007/s10461-017-1956-6] [Medline: 29124420]

32. Determine HIV 1/2 Ag/Ab Combo. Food and Drug Administration, Ministry Health and Welfare, Taiwan. 2015. URL: https://info.fda.gov.tw/MLMS/H0001D.aspx?Type=Lic\&LicId=06015099 [accessed 2020-06-08]

33. Shi L, Kanouse D, Baldwin S, Kim J. Perceptions of HIV/AIDS in one's community predict HIV testing. AIDS Behav 2012 Oct;16(7):1926-1933 [FREE Full text] [doi: 10.1007/s10461-012-0243-9] [Medline: 22767029]

34. Martinez O, Wu E, Shultz AZ, Capote J, López RJ, Sandfort T, et al. Still a hard-to-reach population? Using social media to recruit Latino gay couples for an HIV intervention adaptation study. J Med Internet Res 2014 Apr;16(4):e113 [FREE Full text] [doi: 10.2196/jmir.3311] [Medline: 24763130]

35. Baral S, Turner RM, Lyons CE, Howell S, Honermann B, Garner A, et al. Population size estimation of gay and bisexual men and other men who have sex with men using social media-based platforms. JMIR Public Health Surveill 2018 Feb 08;4(1):e15 [FREE Full text] [doi: 10.2196/publichealth.9321] [Medline: 29422452]

36. Choi EP, Wong JY, Fong DY. The use of social networking applications of smartphone and associated sexual risks in lesbian, gay, bisexual, and transgender populations: a systematic review. AIDS Care 2017 Feb;29(2):145-155. [doi: 10.1080/09540121.2016.1211606] [Medline: 27454158]

37. Delaney KP, Kramer MR, Waller LA, Flanders WD, Sullivan PS. Using a geolocation social networking application to calculate the population density of sex-seeking gay men for research and prevention services. J Med Internet Res 2014;16(11):e249 [FREE Full text] [doi: 10.2196/jmir.3523] [Medline: 25406722]

38. Macapagal K, Coventry R, Puckett JA, Phillips G, Mustanski B. Geosocial networking app use among men who have sex with men in serious romantic relationships. Arch Sex Behav 2016 Aug;45(6):1513-1524 [FREE Full text] [doi: 10.1007/s10508-016-0698-2] [Medline: 26969319]

39. Krueger EA, Chiu CJ, Menacho LA, Young SD. HIV testing among social media-using Peruvian men who have sex with men: correlates and social context. AIDS Care 2016 Oct;28(10):1301-1305 [FREE Full text] [doi: 10.1080/09540121.2016.1178699] [Medline: 27140820]

40. Choi K, Lui H, Guo Y, Han L, Mandel JS. Lack of HIV testing and awareness of HIV infection among men who have sex with men, Beijing, China. AIDS Educ Prev 2006 Feb;18(1):33-43. [doi: 10.1521/aeap.2006.18.1.33] [Medline: 16539574]

41. Vu BN, Green KE, Thi Thu Phan H, Hung Tran M, Van Ngo H, Hai Vo S, et al. Lay provider HIV testing: a promising strategy to reach the undiagnosed key populations in Vietnam. PLoS One 2018;13(12):e0210063 [FREE Full text] [doi: 10.1371/journal.pone.0210063] [Medline: 30596777]

42. Miners A, Nadarzynski T, Witzel C, Phillips AN, Cambiano V, Rodger AJ, et al. Preferences for HIV testing services among men who have sex with men in the UK: A discrete choice experiment. PLoS Med 2019 Apr;16(4):e1002779 [FREE Full text] [doi: 10.1371/journal.pmed.1002779] [Medline: 30973868]

43. LeViere A, Donovan J, Wilkin A, Keller J, Parnell H, Sampson L, et al. Results of a Social Network Testing Intervention for HIV in Infectious Disease Clinics. AIDS Behav 2019 Jan;23(Suppl 1):48-51 [FREE Full text] [doi: 10.1007/s10461-018-2178-2] [Medline: 29872998]

44. Yamanis TJ, Dervisevic E, Mulawa M, Conserve DF, Barrington C, Kajula LJ, et al. Social Network Influence on HIV Testing Among Urban Men in Tanzania. AIDS Behav 2017 Apr;21(4):1171-1182 [FREE Full text] [doi: 10.1007/s10461-016-1513-8] [Medline: 27506817]

45. Veinot TC, Caldwell E, Loveluck J, Arnold MP, Bauermeister J. HIV Testing Behavior and Social Network Characteristics and Functions Among Young Men Who have Sex with Men (YMSM) in Metropolitan Detroit. AIDS Behav 2016 Nov;20(11):2739-2761 [FREE Full text] [doi: 10.1007/s10461-016-1296-y] [Medline: 26837634]

46. Fuqua V, Chen Y, Packer T, Dowling T, Ick TO, Nguyen B, et al. Using social networks to reach Black MSM for HIV testing and linkage to care. AIDS Behav 2012 Feb;16(2):256-265 [FREE Full text] [doi: 10.1007/s10461-011-9918-x] [Medline: 21390535]

\section{Abbreviations}

FB: Facebook 
GSN: geosocial network

IRR: incidence rate ratio

MRT: mass rapid transportation

MSM: men who have sex with men

PEP: postexposure prophylaxis

PrEP: pre-exposure prophylaxis

PSM: propensity score matching

VCT: voluntary counseling and testing

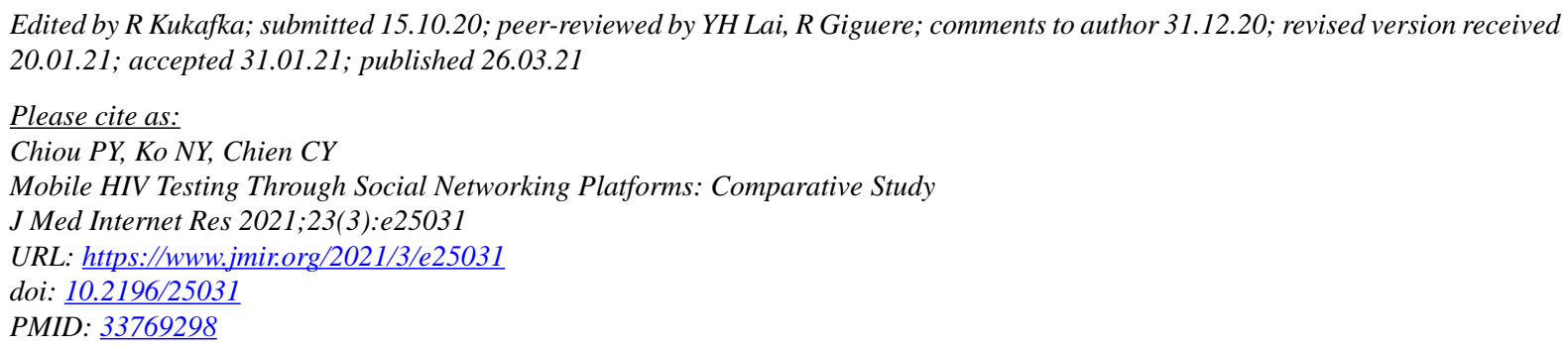

(CPiao-Yi Chiou, Nai-Ying Ko, Chien-Yu Chien. Originally published in the Journal of Medical Internet Research (http://www.jmir.org), 26.03.2021. This is an open-access article distributed under the terms of the Creative Commons Attribution License (https://creativecommons.org/licenses/by/4.0/), which permits unrestricted use, distribution, and reproduction in any medium, provided the original work, first published in the Journal of Medical Internet Research, is properly cited. The complete bibliographic information, a link to the original publication on http://www.jmir.org/, as well as this copyright and license information must be included. 